\title{
CIRUJANO LICENCIADO PEDRO LÓPEZ DE LEÓN Y SU LIBRO PRÁCTICA Y TEÓRICA DE LAS APOSTEMAS (SIGLO XVII)*
}

Hugo A. Sotomayor Tribín MD**

\section{Resumen}

Se presenta la primera iconografía de instrumentos quirúrgicos empleados por los cirujanos españoles, dibujada después de varias décadas de ejercicio profesional del cirujano Pedro López de León en Cartagena de Indias y publicada por primera vez en 1628 en Sevilla, así como unas notas sobre las prácticas urológicas que este cirujano tuvo en esa ciudad.

Los dibujos y en general la obra quirúrgica constituyen el primer referente quirúrgico español en lo que hoy es Colombia y tal vez el primero de toda América.

\section{SURGEON PEDRO LÓPEZ DE LEÓN AND HIS BOOK: PRACTICAL AND THEORETICAL ELEMENTS OF APOSTEMAS (17TH CENTURY)*}

\section{Abstract}

The first iconography of the surgical instruments used by Spanish surgeons is here-in shown. Drawn after several decades of professional practice of Surgeon Pedro López de León in Cartagena de Indias and published for the first time in Seville in 1628. This document also includes some notes on urologic practices that this surgeon performed in this city. The drawings and the surgical work are the first Spanish surgical reference in what is currently Colombia and probably the first in America.

\section{Introducción}

Las fuerzas expedicionarias españolas, desde los mismísimos viajes de Colón, estuvieron acompañadas de empíricos, cirujanos y médicos. La mayoría de ellos no dejaron escritas sus experiencias. Sin embargo, de lo que hoy es Colombia se conoce un texto de la segunda mitad del siglo XVI y dos de principios del siglo XVII. El primero constituido por el libro del soldado español Bernardo de Vargas Machuca, titulado Milicia y descripción de las Indias, que terminó de redactar en 1595, pero sólo se publicó en Madrid en 1892. Los escri- tos de principios del siglo XVII están compuestos por el libro del licenciado médico portugués Juan Méndez Nieto, titulado Discursos medicinales terminado en Cartagena de Indias en 1607, remitido a España para su publicación que se hizo en forma facsimilar por primera vez en el siglo XIX y general en 1989, y por el libro del cirujano español Pedro López de León, Práctica y Teórica de las apostemas (Figura 1), publicada por primera vez en Sevilla en 1628.

La presentación de los dibujos sobre objetos médicos y la selección que se hace de algunas notas escritas por
Fecha recibido: agosto 19 de 2008 - Fecha aceptado: septiembre 10 de 2008

* Primera iconografía de instrumentos quirúrgicos en América y extractos de algunas de las primeras notas de urología y odontología elaboradas y escritas en Cartagena de Indias, por el licenciado Pedro López de León, Cirujano de la ciudad de Cartagena de Indias en su libro Práctica y Teórica de las apostemas (finales del siglo XVI, principios del siglo XVII).
** Profesor de Historia de la Medicina y de Antropología Médica, Facultad de Medicina, Fundación Universitaria de Ciencias de la Salud, FUCS. Bogotá D.C.Colombia. Miembro de Número de la Academia Nacional de Medicina. Miembro Activo de la Sociedad Colombiana de Historia de la Medicina. 
Pedro López de León alrededor de la urología y la odontología, constituyen la cuarta referencia que en total ha podido hacer el autor del presente artículo de diferentes pasajes médico quirúrgicos de la obra de López de León. La primera la hizo en el libro Guerra, enfermedades y médicos en Colombia, la segunda en el libro del que es autor principal, El Medicamento en la historia de Colombia, y la tercera en el capítulo titulado Sífilis y pián: a propósito del morbo gálico en la obra de Pedro López de León, Cartagena de Indias de finales del siglo XVIy comienzos del XVII, aparecido en el libro Temas Médicos, Volumen XVI de la Academia Nacional de Medicina. ${ }^{1,2,3}$

Existe la interesante publicación de Jairo Solano Alonso Salud, cultura y sociedad en Cartagena de Indias, siglos XVI y XVII, en donde se analizan las obras de Juan Mendez Nieto y Pedro López de León en el contexto científico y social de la época. ${ }^{4}$ Fue Pedro López de León un distinguido licenciado en cirugía graduado en Sevilla, discípulo del famoso profesor de esa disciplina Bartolomé Hidalgo de Agüero. Dejó en su importante obra Práctica y Teórica de las apostemas - escrita durante casi treinta años de ejercicio profesional en Cartagena de Indias, publicada por primera vez en 1628 en Sevilla y reeditada cinco veces - importantes descripciones de enfermedades conocidas hoy como el escorbuto, disenterías, pleuritis, bocio y lo que en aquellos años se llamaba indistintamente morbo gálico, bubas, enfermedad serpentina o sífilis, además de excelentes descripciones de procedimientos quirúrgicos, dibujos de los instrumentos que usó y fabricó en esa ciudad y un maravilloso antidotario o lista de medicamentos y formas de usarlos.

Los objetos de cirugía representados en esta obra constituyen la primera referencia iconográfica de los instrumentos quirúrgicos usados por los españoles en lo que hoy es Colombia y en toda América. Entre ellos se pueden reconocer en los dibujos identificados con los números 1,9 y 13 aquellos cortantes de tipo escoplos; en los 2, 3 y 12 diferentes tipos de cuchillos, en el 8 una segueta, con el número 28 un conjunto de veintidós tipos de cauterio y como 29, 30, 31 y 32 unos cauterios con sus cañas a decir de López. Los objetos identificados como 34, 35 y 36 parecen ser unas ventosas. Con los números 20, 21 y 22 parece que el cirujano Pedro López de León quiso representar elementos para reducir fracturas y/o hacer amputaciones de los miembros inferiores y superiores.

La iconografía de estos instrumentos quirúrgicos es de gran valor si se recuerda, a decir del museólogo médico Felipe Cid, que su existencia antes del siglo XVI es escasa y que el primer catálogo conocido de armamentario quirúrgico es de Scultetus, publicado en 1665 y que a este le siguieron dos más hasta la producción fabril de los instrumentos quirúrgicos en el siglo XIX, el de Garangeot que vio la luz en el año de 1727 y de Brambilla editado en 1787. 5 López de León al igual que todos los cirujanos y médicos de su época perteneció a la tradición galénica. El cita en forma reiterada a Hipócrates, Galeno y a Avicena. Mostró además los objetos y los pasos seguidos en la forja de los instrumentos ferrales por él usados.

Aunque los instrumentos quirúrgicos de hierro forjado se conocieron en la época de la medicina clásica europea, el material férrico reemplazó de modo definitivo al bronce a partir del siglo XV. Los de hierro forjado además de tener bordes cortantes defectuosos, se dañaban rápido por la corrosión acelerada. Estas razones son las que explican su casi inexistencia en la alta y baja edad media europea (Cid, 2007: 502). En el siglo XVI, en el que se educó Pedro López de León en Sevilla, las nuevas técnicas empleadas para mejorar "el temple del hierro forjado -conducciones de agua, chimeneas más altas, utilización de carbón vegetal, hornos convectores, temperaturas que alcanzaban los mil grados, etc- revirtieron en la obtención de un material con mayor dureza y elasticidad" (Cid, 2007: 502).

Los instrumentos quirúrgicos a decir de Cid, se dividen en los siguientes grupos básicos: cortantes (como cuchillos, bisturíes, tijeras o sierras), separadores (erinas, ganchos, espéculos, valvas, dilatadores), punzantes (agujas finas rectas y curvas), prensores (pinzas de disección, hemostáticas), escarificadores (curetas) y reparadores (agujas de sutura y lino, catgut, y otros) (Cid, 2007: 495).

Hoy se sabe que los instrumentos quirúrgicos fueron el producto de artesanos hasta finales del siglo XVIII y que ellos durante el siglo XVI y XVII en los que vivió y 
HISTORIA DE LA MEDICINA

trabajó Pedro López de León, se usaron también en las prácticas autópsicas. Según el museólogo mencionado los conocidos en el siglo XVI eran el cuchillo de disección, tijeras corrientes, sierra de arco, punzón, tenazas, sondas exploradoras, separadores, cizallas, pinzas, fórceps para extraer municiones y otros objetos, costótomo, raquiotomo, escoplos y lancetas para las sangrías y escarificaciones (Cid, 2007: 384).

\section{Material}

El que aquí se presenta está constituido por los primeros dibujos conocidos de objetos quirúrgicos y elementos ortopédicos realizados por un cirujano, Pedro López de León, vivió en lo que hoy es Colombia, y por algu-

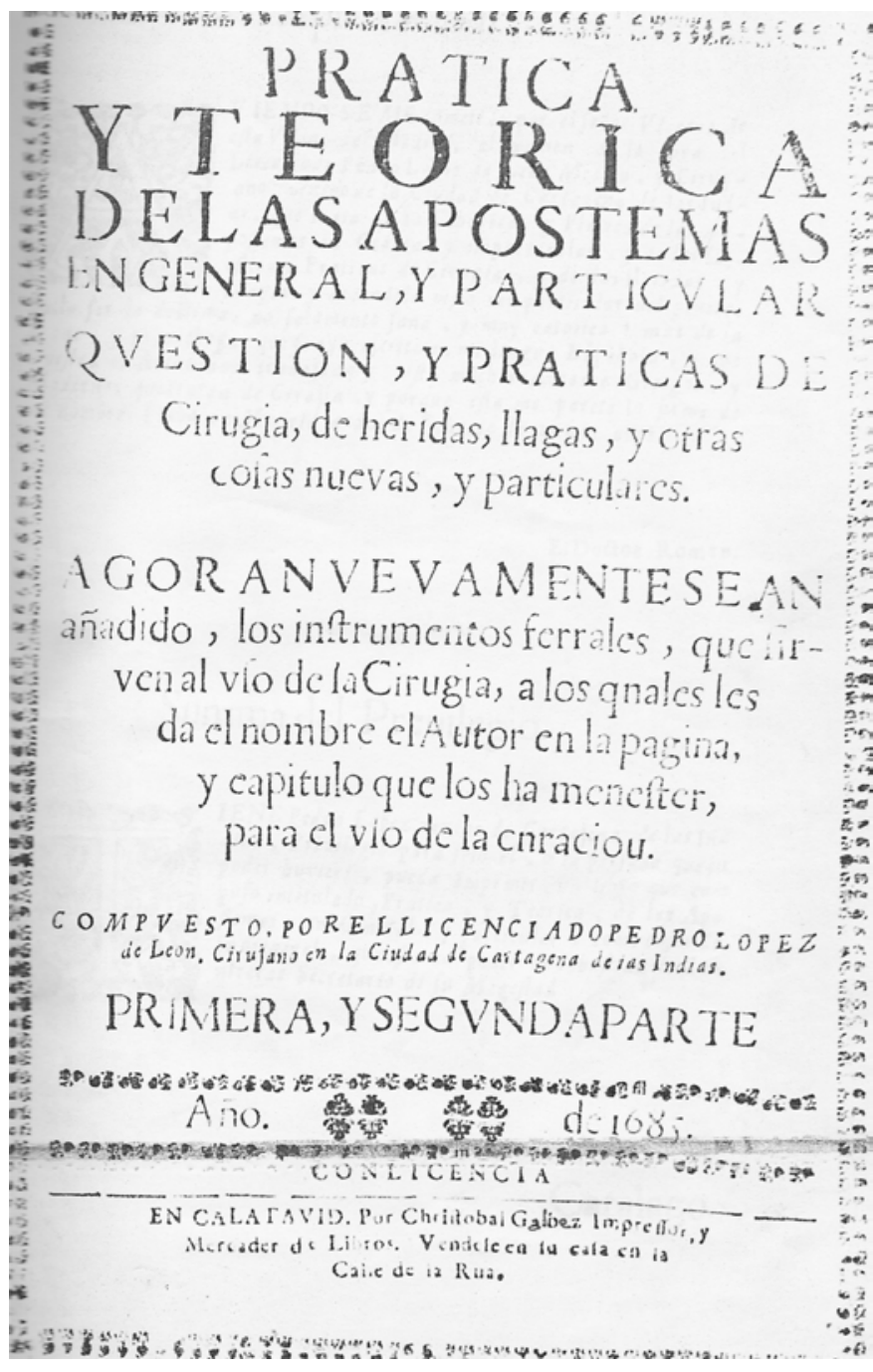

Figura I. Portada del libro. nas de sus notas sobre su práctica urológica y odontológica (Figuras 2, 3 y 4).

\section{Objetos quirúrgicos}

Pedro López de León escribió notas muy importantes sobre los diferentes tipos de cauterio que usó en su práctica en Cartagena de Indias: "He puesto dibujados en las láminas al fin de este libro (en el) número 28, para los Cirujanos romancistas, esta variedad de cauterios actuales, que los autores traen para diferentes partes del cuerpo, y unos sirven para llagas podridas de las canillas y piernas, los cuales son cuadrados, y triangulares; otros hay como media caña, para las canillas y huesos de los brazos; hay otros llamados datilares, para el miembro viril, y otras vísceras. Otros hay incisorios que cortan, llamados cuchillares para cortar, y otros para abrir los abscesos, como hierro de lanza; y otros cuadrados, y con punta, para lo mismo. Otros de forma de medio corazón, para abrir apostemas entre las costillas, en la cavidad vital, y en el hígado. Y otros hay como media luna, para las hernias; otros para hacer fuentes con su hembra y para echar sedales. Otros de cinco, $y$ de cuatro puntas, para el dolor ciático, cuando es antiguo. Otros hay puntiagudos con su cánula, para las fístulas del lagrimal, y otros hay de diferentes maneras, para que diestro Cirujano los acomode, y aplique conforme los casos le sucedieren. Y es bien este proveído de todos estos cauterios, y muchos más, que son menester, porque no le falten en el tiempo de la mayor necesidad, y esto deben hacer todos los Cirujanos cuerdos, y sabios; y el Cirujano que le faltan las herramientas, que su arte manda, no le llaméis sino medio Cirujano, que este nombre merece, y como el Carpintero sin escuela. La forma, y modelo de los cauterios actuales con sus cañas, para quemar el hueso, se hallara(n) (en los) números 29, 30,31 y $32 "{ }^{6}$

\section{Tablillas ortopédicas}

Como buen cirujano de su época se enfrentó con los problemas de dislocaciones y fracturas óseas y uso de las técnicas conocidas para su reducción: "Yadviértase, 
que puesto el hueso en su lugar, las tablillas le hacen permanecer en él si están bien ajustadas, y apundiadas, como tengo dicho... como lo echaréis de ver en la figura de la pierna, que hallaréis pintada en (los) números 19, 20 y 21, de las láminas, al fin de este libro... " (López de León 1685: 309).

\section{Algunas notas sobre urología}

En los siglos XVI y XVII la enseñanza de la medicina estaba divorciada de la cirugía. Los cirujanos no disfrutaban de una posición social considerable. La urológica estaba centrada todavía en la operación de la talla y en la curación de las carnosidades del aparato urinario.

Gracias a la enciclopedia Historia Universal de la Medicina dirigida por Pedro Laín Entralgo, se sabe que "El ejercicio de ciertas intervenciones urológicas, muy concretamente la operación de la talla, estuvo reservado, durante el Renacimiento, a ciertos empíricos, los llamados litotomistas; en España estos prácticos incluso obtuvieron autorización de las Cortes para el ejercicio de sus profesiones".

En la historia de la urología renacentista fue fundamental la contribución hecha por el cirujano español Francisco Díaz, autor de una exposición sistemática y en buena parte original de las afecciones urogenitales en su Tratado de todas las enfermedades de los riñones, vexiga y carnosidades de la verga y vrina, editado en Madrid en 1588 y reimpreso en la siguiente centuria, en 1627 y 1643 . La práctica de la talla "a la italiana", descrita por el autor es la técnica ideada por Battista da Rapallo. El capítulo más importante es la exposición que en el tercer tratado hace de la clínica y el tratamiento de una afección muy común en ese siglo: las carúnculas o "carnosidades endouretrales". Ya había hecho una valiosa contribución al tema Andrés Laguna en su libro Methodus cognoscendi extirpandique excrescentes in vesicae collo carunculas (Roma 1551), anterior a las exposiciones de Amatus Lusitanus y Alfonso Ferri. ${ }^{7}$

Para el tratamiento de las "carnosidades" se propugnó el uso de "candelillas" portadoras de sustancias cáusti- cas. La prioridad en la invención y utilización de tal recurso terapéutico fue motivo de controversia en esa época. Los cirujanos españoles, y antes que ellos Paré y Andrés Laguna, atribuyeron la invención a un empírico de nombre Maese Felipe, en tanto que Amatus Lusitanus defiende la prioridad de su uso a favor de Lorenzo Alderete, profesor de Salamanca. De la iniciación de tal cura, Francisco Díaz relata que tuvo lugar en Alemania donde el cirujano Maese Felipe atendió al entonces emperador Carlos, afectado del mal de carnosidades con supresión de la orina y confirmado con sondajes la naturaleza del mal, buscó aplicar sobre aquéllas cáusticos que las pudiesen corroer valiéndose de una candela de cera para introducir el medicamento; un mancebo boticario aprendió de Maese Felipe la cura y la difundió en Roma donde la conocería el boticario portugués Alfonso Díaz, quien a su vez, titulándose "doctor Romano", la introdujo a España. El tratamiento de las carúnculas endouretrales se buscó también alcanzarla con procedimientos quirúrgicos, utilizando adecuados instrumentos cisorios. La posibilidad de tal intervención aparece indicada en el texto urológico de Alfonso Ferri; Paré, por su parte, ideó el instrumental propio para su ejecución; la técnica para practicar la uretrotomía expuesta por Francisco Díaz difiere de la propugnada por Ambroise Paré y ha sido la que con ligeras variantes se ha mantenido hasta el siglo XIX. ${ }^{8}$

La urología como materia no se enseñaba en las facultades de medicina de la España del siglo XVI.

Las siguientes descripciones son fieles transcripciones, ajustadas a la grafía actual, tomadas de la obra de Pedro López de León, Práctica y teórica de las apostemas, publicadas en 1628, y de la edición de 1685 en Calatayud, España.

\section{De las apostemas de la verga}

"En la cura de las inflamaciones, o apostemas de la verga, siendo de causa caliente, se ha de empezar sangrando, habiendo fuerzas para ello. Será pues la primera sangría del brazo derecho de la vena del arca, y luego del otro brazo; y si fuere menester sacar más sangre para deponer la plenitud, será del tobillo. La dieta será sutil, coma pollos pequeños, lechugas, almirones, calabaza, bledos, 


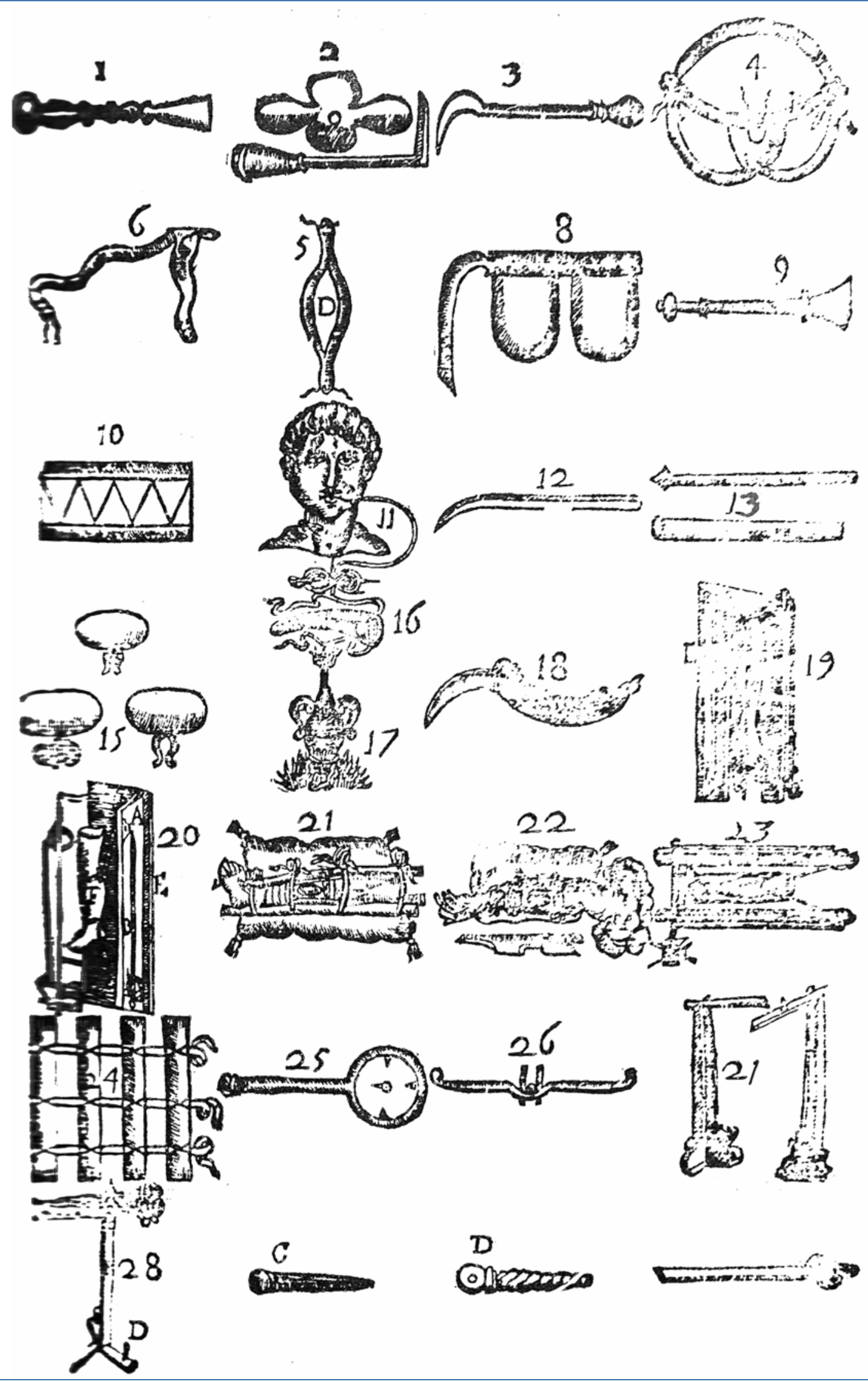

Figura 2. Diferentes instrumentos quirúrgicos usados por Pedro López de León en Cartagena de Indias entre I59I y 1628. 

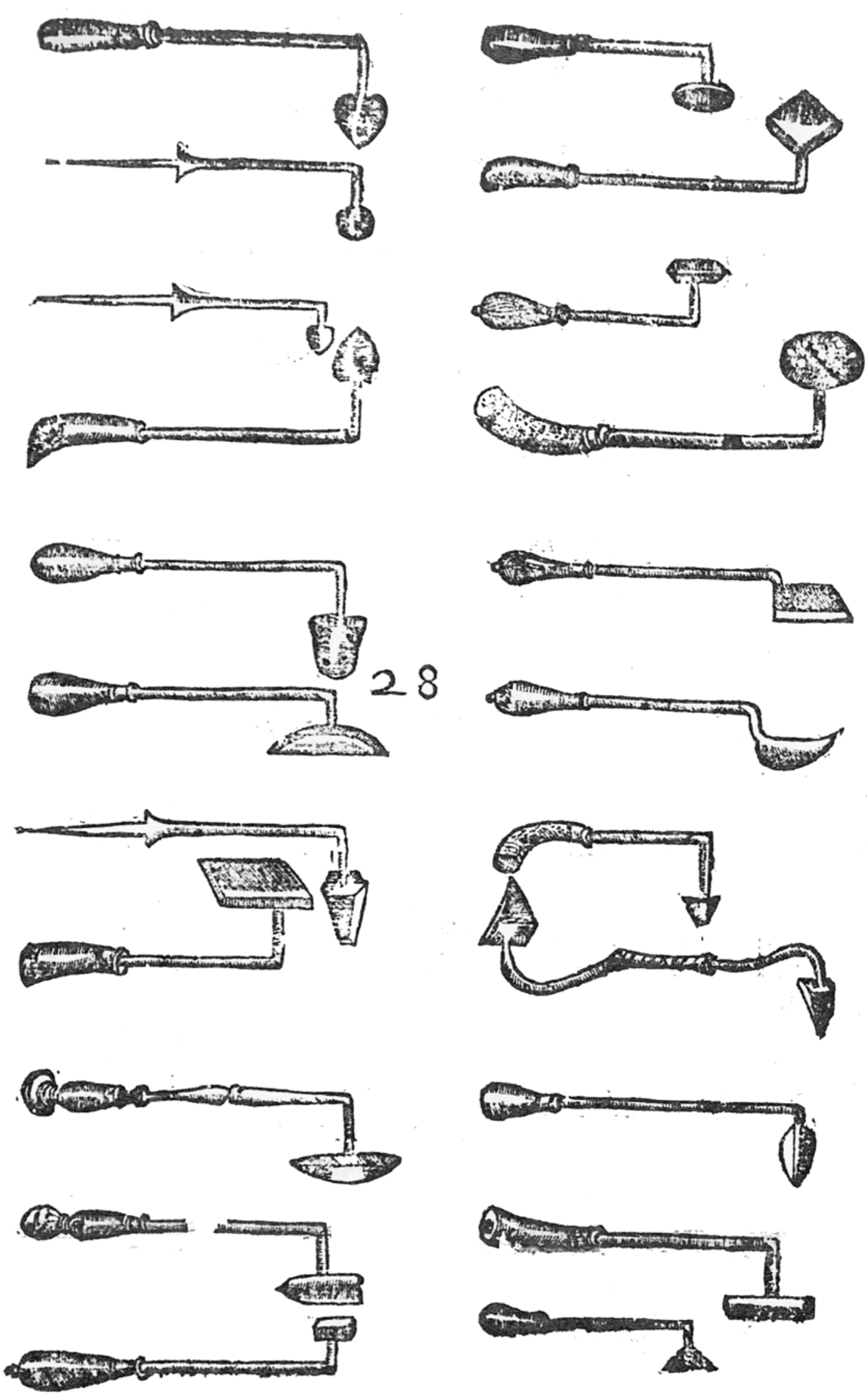

Figura 3. Diferentes cauterios usados por Pedro López de León en Cartagena de Indias entre I59| y I628. 


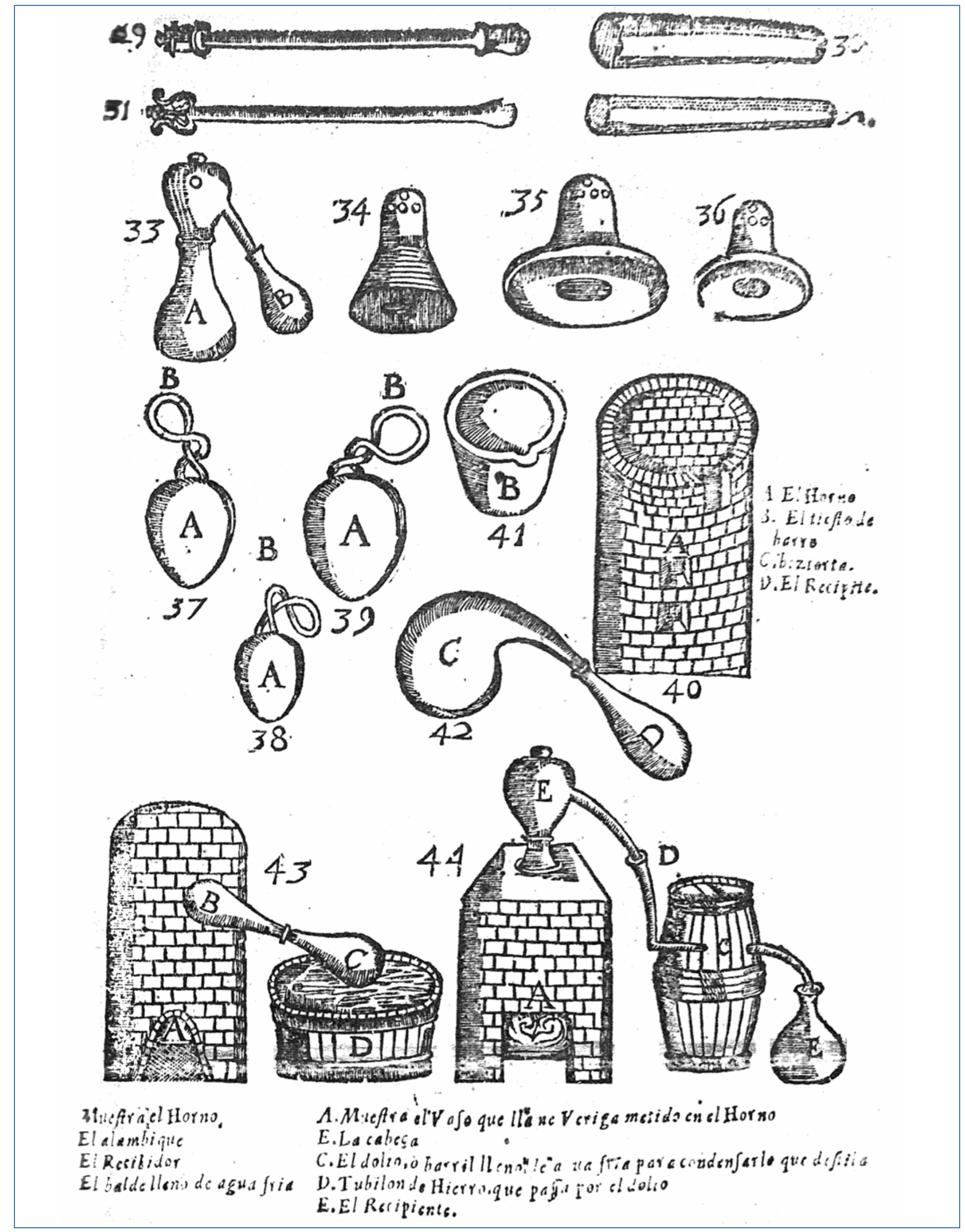

Figura 4. Objetos para la forja de sus instrumentos quirúrgicos de hierro o ferrales. 
almendradas, huevos frescos, beba agua fría, o de cebada, manzanas asadas..."(López de León, 1685: 98).

"En Cartagena de las Indias, me sucedió, yendo sirviendo en las galeras a su majestad, el año de 1591, a Nombre de Dios, el capitán de esta era Lorenzo Roa, mandó estropear a un forzado, pusieronle una talega, con dos balas de caños de crusia colgadas de los testículos, y de esta manera lo subieron a la antena, y allí lo tuvieron un cuarto de hora, bajáronle, con el escroto más negro que una pez, luego se lo sajé profundamente, y lavele con agua salada, y vinagre tibio, y con el emplasto de harinas con oximiel, y sangría que hice de los brazos, y sin mudar intención se cayó el escroto a partes, y quedaron los testículos desnudos. Luego le puse en planchuelas, el mundificativo de nervios, añadiéndole un poco de ungüento egipcíaco, por no estar la llaga bien mundificada: después de mundificada le curé con solo hilas secas, y un pegado de ungüento basilicon, por conservar la humedad natural de la parte acabó de sanar con un pegado de diapalma, abajado con aceite rosado" (López de León 1685: 100).

\section{De las apostemas de los testículos y el escroto}

"Las apostemas de los testículos llaman los médicos antiguos, y modernos hernias, las cuales se dividen en muchas especies. Tres son las más principales, hernia, intestinal, y cirbal, y carnosa... Aquí no tratamos ahora de estos tumores, sino tan solamente de las inflamaciones que suelen venir a los testículos, y al escroto, por el flujo de humores calientes...

Las causas y señales de estas inflamaciones de los compañones, y del escroto son las mismas, que de las demás inflamaciones. La cura se ha de empezar así en las inflamaciones de los testículos, como en las del escroto, porque todas demandan una misma cura, y así lo primero que habéis de hacer, es ordenar la vida al enfermo, sangrando, reveilendo, y evacuando, y purgando con medicinas lenitivas..."(López de León 1685: 98).

\section{De las úlceras del pudendo, partes genitales}

"Ya sabéis como estas úlceras proceden por la mayor parte de contagio, y así esta cura se ha de re- mitir a la cura del morbo gálico, porque lo demás es ganar tiempo con daño notable del paciente, sus causas, y sus señales a todos lo cirujanos son manifiestas por sus accidentes, y relación con el enfermo, y así las úlceras del hueso pubis, y del miembro viril, y de los genitales, todas tienen dependencia de la gálica, no se entiende por esto que deje de haber algunas sin contagio, que yo he curado más de seis, en personas harto continentes, y castas, y de mucha virtud de úlceras, en estas partes dichas, que han procedido de derivación de los miembros superiores, que arrojaron el humor a las partes hemorroidales, pero de estos muy pocos" (López de León 1685: 283).

\section{De las úlceras de la vulva, o natura}

"Ya sabéis cuan delicadas son las partes mujeriles, pues por vergüenza o descuido hemos visto muchas mujeres morir desafortunadamente. Pudiera contar historias acerca de esto muy notables, pero adelante trataré algo de casos peregrinos que me han sucedido en la vulva, o natura de la mujer, y en la madre, en donde se suelen hacer úlceras contagiosas, podridas o corrosivas, y torcidas, cancerosa tumores chicos, y grandes, que no parecen sino que están preñadas, y algunas lo creen, y aparejan la canastilla, hasta que el tiempo las desengaña, y para socorrer, y remediar todo lo dicho, ordenaréis la vida, dándole jarabes, y purgando, conforme fuere, a la calidad de la úlcera, evacuando el humor pecante de todo el cuerpo..." (López de León 1685: 285).

\section{De las regadías, y condilomas}

"Las regadías son unas grietas, o hendiduras a lo largo, con llaga y tumor, con mucho dolor, y ardor, causado del humor acre, y salado seco, y esta enfermedad tiene contraído, y cerrado el sieso, y el cuello de la madre, que son los lugares donde suelen venir. También suelen venir en el miembro viril, y en los labios de la boca, y en los pezones de las tetas, cuando crían las mujeres..." (López de León 1685: 289). 


\section{De la gonorrea virulenta}

"Las materias que suelen purgarse por el caño de la orina, se llama a este efecto gonorrea virulenta, el cual difiere de la estanguria, porque esta hecha materias hediondas, y la estanguria, hecha un humor como seminal, que carece de mal olor si el mal es fresco, no hay que mucho caudal de él, sino es ordenar la vida en la comida, y bebida, excusando el coito, y no beber vino, que con solo esto bastará para tener salud el paciente. Y si el mal es viejo, y la purgación demasiada, con estilicido, o materias coloradas o libiadas, crudas, como aguas hediondas, suelen dejar el caño de la orina con llagas, por razón de la acrimonia, y inflamando los genitales, y causan dolor en el hueso pente. La gonorrea verdadera, es una purgación de solo la simiente, que se le sale sin sentir, de la sangre que acude de todo el cuerpo, a los genitales, la cual se detiene, ni actúan, por causa de la resolución, y de la parálisis que le viene a la facultad retentiva. Así lo dice Galeno: suele también venir a este efecto de la sangre, y materia seminal, que de todo el cuerpo por los vasos seminales les cuela...Suele venir esta gonorrea a los hombres dados mucho al coito, mayormente si trataron con mujer sucia, lastimada de morbo Gálico, o quien tiene ella la misma purgación, o llagas en la vulva, o que esté con su regla, comunicase este afecto y vapores malos a los testículos, mediante el acto venéreo, y la sangre acude a los testículos para su nutrimento, y simiente, la cual se corrompe, y hace las materias venenosas".

\section{La cura de la gonorrea}

"Si el cirujano fuere llamado para esta cura, empiece con sangrías, y dieta, habiendo pletroria, evitando todo lo que puede inflamar la sangre, así como los diuréticos, y flatulentos, sangrar, y purgar aprovecha mucho, habiendo malos humores. Hace de huir el coito, y las poluciones de noche, causadas de molicies. Si la materia que saliere fuere simiente, es mala señal; pondréis diligencia en evitar todo lo que puede engendrar en nuestro cuerpo abundancia de simiente, porque estimulan el daño venéreo, y absténgase de beber vino, y si tuviere mucha necesidad de beberle, sea blanco, y blando aguanoso, $y$ vino austero, de buena fama, y bien aguado, huya de tener conversaciones con mujeres, y de pensar mucho en ellas, que son peores que peste, que solo el aire inficiona. El ejercicio moderado aprovecha, y sea de manera, que mueva sudor; el sueño poco, untaréis los lomos, y los genitales con cosas frescas, así como ungüento rosado, y refrigerante de Galeno, y después de untado, pondréis pañitos mojados con oxicrato, que es agua, y vinagre, $y$ váyanse mojando, como se fuere enfriando, digo desecando, y luego acudiréis con confortativos medicamentos astringentes, así de dentro, como por de fuera. Meta el paciente los testículos en agua cosida con azederas, y lechugas, verdolagas, y cebada..."(López de León 1685: 305).

\section{Algunas notas sobre odontología}

Las dolencias de los dientes, de la lengua, los labios, encías, glándulas salivares, los carrillos y la mandíbula fueron un problema que desde el tiempo de los griegos y árabes se enfrentaron de variadas formas. Estos últimos hicieron uso liberal de las técnicas cauterizadoras. Pedro López de León como buen cirujano se enfrentó a los problemas de la cavidad oral, de la dentadura y las dislocaciones mandibulares.

\section{De las apostemas de la boca llamadas Parulida}

"Este aspecto es pasión de las encías. En las cuales se crían unos tumorcillos pequeños, a los cuales los Griegos llaman Parulidas, engendranse de humores viciosos corrompidos. Tiene causa externa, por ser el tiempo caliente, y húmedo, y causa interna, de humores, que acuden de todo el cuerpo, y bajan de la cabeza. Este aspecto se comprende debajo los universales remedios, que acerca del ordenar de la vida tenemos escrito, así de jarabes, sangrías, y revulsiones, purgas; y así de los medicamentos locales, es justo tratemos de ellos, los cuales han de ser, que quiten el dolor, resolviendo y madurando ...Si se abrieren estos tumorcillos, los untaras con miel rosada, y si fuere menester mayor mundificación, el ungüento egipcíaco con vino: la miel rosada con vino, y sarcocola mixto es buen remedio". 
"Suelen doler los dientes de causa caliente. Por la mayor parte este dolor suele venir por mala complexión, con materia, o sin ella, en una de tres partes se siente este dolor, unas veces duele la sustancia del diente, o muela, o la encía, o el nervio que se planta en la raíz del diente, y esto es lo mas recebido de todos los prácticos, que duela la sustancia del hueso (....) Si el dolor es intolerable, el mejor remedio que yo he hallado, de que tengo mucha experiencia, es hacer una píldora de opio, y traerla en la boca sobre la muela, o diente que padece el dolor, y escupir la saliva que hiciere, y no tragarla, porque hará mucho daño al ventrículo...Si el diente o muela que duele, está sano, dase el cauterio encima de ellos, sin llegar a las encías; y este calor del cauterio consume toda la humedad putrefaciente que hay hasta la raíz, y queda confortada la parte. Si todo estos no aprovechare, dice Alfaravio (Alsarabio), que se saque la muela, o diente, porque es imposible de otra manera quitar el dolor. Suele alguna vez salir entre diente, y diente una carnosidad que crece como un garbanzo, hasta ser tamaña como un huevo, la cual tiene su origen de las encías; llamase esta carnosidad epulide, suele degenerar en canero, el cual hecha una virulencia hedionda, y la carne tiene un color aberengenado, o negro. A esta tal no le toquéis con obra manual, que se os cancerará, toda la mandíbula, y gaznates, como yo he visto en Sevilla. El método curativo que se ha de tener en este afecto, es ordenar la vida, dando jarabes, y purgando, sangrando, echando ventosas, y haciendo fricaciones. Tomarás un hilo doblado, y torcido lo infundirás en agua caliente, y un poco fuerte, luego se enjugue a la sombra, se ate con ella la carnosidad, y se vaya apretando, hasta que se caiga. Si fuere menester sacar uno, o dos dientes, para hacer esta obra bien hecha, se quemará la carnosidad con el aceite de vitriolo, o con el agua fuerte de dorar, y caída la escara, se usará de lavatorios desecantes, o quemarla con el cauterio actual, metido en su cañoncito, y guarnecidos los demás dientes con paños mojados en agua fría".

\section{De la ránula}

"Ránula es un tumor que nace debajo de la lengua, que impide el uso del hablar, la cual se llama de los griegos batrachium, y de los latinos ránula, que no parece sino que es otra lengua, de humores fríos, y viscosos se hace, que del cerebro se regogen en la lengua, y lo que tiene dentro es de color, y consistencia de huevo, y si el color de la Ránula, es de color cetrino, su cura sera radicativa, abriendo el tumor con hierro, así como el escalpelo, o verduguillo."

"En esta Ciudad de Cartagena curé dos esclavos de dos Ránulas muy grandes, que tenían como dos lenguas; y otra curé en Santa Marta el año 1613 que fue llamado de Don Diego de Argote Gobernador de aquella Ciudad, para curarle del morbo gálico, que lo tenía maltratado: de camino curé un encomendero, de una Ránula grande, xaropelo, y purguelo, y sángrele de los brazos, luego le abrí la Ránula con un cauterio de fuego, salio de alli un humor albugino. Pasados cuatro días le curé siempre con polvos de Iuanes metidos con lechinos, y sus desensivos por de fuera de claras de huevos, y aceite rosado; con todas estas prevenciones se (hizo) de manera, que me obligó de nuevo a sangrarle dos veces de la cefálica, y sacarle bien sangre, y hechale cristales agudos, y hacerle fuertes fricaciones, y echándole ventosas con sajas, y con sin ellas Ordenele este lavatorio...Ambrosio Parco(Paré) trae una lámina de hierro para dar este cauterio sin daño de la lengua, es bueno, porque se hace la obra sin quemar la circunferencia, cuya forma está (en el dibujo) número 2" (López de León 1685: 89).

\section{De las úlceras en la boca}

"Ya sabéis que los universales remedios por la naturaleza del humor han de preceder siempre; y luego los medicamentos tópicos; $\mathrm{y}$ ansí trataremos dellos, advirtiendo, que los que hemos escrito, y enseñado en el capítulo de ulceras de vulva, o natura, son a propósito para estas porque si la úlcera es corrosiva, y de humor caliente, y mordás, los siguientes remedios son a propósito... Y si fueren generadas del morbo gálico, como lo son las mas deste lugar, precediento buena evacuación porsar y purgar, siendo conveniente damos a beber el agua de guayacán, y los mas seguro, y breve, es tomar la unción azogue, porque las partes internas las confirma, y rectificar, y las ulceras...y cicatriza.....Si la úlcera fuere en el paladar, acudiréis con grande diligencia, y cuidado, como esta dicho; metiendole en las unciones del mercurio, o asogue. O poniendole los par- 
ches; o dándole el bocadillo del precipitado, que son polvos de Iuanes, o las píldoras dominicales, o las de mercurio, de nuestra intención que traemos en el antidotario escritas....El remedio que tiene, es suplir con el arte la falta del hueso, tapándolo con hilas, o con cera, o con plata, o con oro, haciendo unas chapillas con su asita en medio, por la cual entre un pedacillo de esponga, y metella por el agujero, de modo que la esponga encaje dentro, y hinchándose con la humedad, se tiene la chapilla, sin caerle, de tal manera, que hablan con gusto, y se come, y beve, sin que se salga nada por las narices, de que yo tengo mucha experiencia por aver hecho arras... "(López de León 1685: 278).

\section{De las dislocaciones en particular}

"Las quijadas, o mandíbulas se desencajan, y salen de su lugar de una de dos maneras, a dentro, o afuera; así lo sienta Albucasis, y Oribacio, Galeno, Hipócrates y otros doctores. Las señales de que salió la mandíbula hacia fuera, son cuando la boca se quedó abierta y no la pueden cerrar, y los dientes de la quijada de abajo están más salidos hacia fuera que los de arriba. Las señales de las dislocaciones hacia dentro, son cuando la boca queda cerrada y tanto que nadie la puede abrir, por fuerza que haga, y no puede el paciente hablar palabra. Esta dislocación jamás la he visto en 48 años que ha que sigo Hospitales y he asistido en la Ciudad de Sevilla, donde hay tantos casos que ver, y entiendo que no debe de haber cirujano que la halla visto. La dislocación hacia fuera se restaura de esta manera: Meteréis los dedos pulgares dentro de la boca del paciente, poniéndolos encima de las muelas bajas postreras, apretando fuertemente hacia abajo, y a un tiempo, y en el mismo punto bajaréis la quijada, y con todos los demás dedos que habéis de tener arrimados debajo de la barba, alzaréis las partes delanteras de la quijada con fuerza hacia arriba; y luego encaja el hueso en su lugar, sino es que el tal enfermo esté contaminado de la cuarta especie de bubas. Y si de esta manera no pudieres restaurar la quijada a su lugar, en lugar de los dedos pulgares pondréis sobre las muelas dos palillos delgados, uno de cada lado, y apretaréis fuertemente hacia las mue- las gordales, de manera que haga bajar de aquella parte la mandíbula, o quijada, y luego pondréis de bajo de la barba una faja recia y subiréis los cabos de la faja hacia arriba, guiándolos por encima de las orejas, y tiraréis fuertemente hacia arriba por encima de la cabeza con sagacidad, y prudencia, procurando que el que tirare sea practicante, o persona que lo entienda, porque se ha de tirar con igualdad, y al tiempo que tirare el ayudante con fuerza de los dos cabos de la faja, o venda poniendo sus dos rodillas sobre los hombros del paciente, estando por detrás el ayudante, y el Cirujano aprieta las dos cuñas, o palillos, y la quijada juntamente hacia abajo, con fuerza, y de esta manera se restaura esta quijada" (López de León 1685: 299).

\section{Discusión y conclusiones}

Los dibujos de los objetos quirúrgicos y las transcripciones sobre las consideraciones urológicas y odontológicas de Pedro López de León escritas después de muchos años de ejercicio profesional en Cartagena de Indias son unos documentos de gran valor para la historia de la medicina y la odontología en Colombia. ${ }^{9}$ Los dibujos de los instrumentos quirúrgicos de hierro y de los procesos para su elaboración son, a no dudarlo, de un enorme valor dentro de una perspectiva museológica médica general y colombiana en particular. Ellos no tienen émulos en la historiografía médica colombiana de los siglos XVII, XVIII, XIX y XX. Al lado de esos instrumentos quirúrgicos pueden figurar los objetos descritos en el testamento, de 1633, del barbero Juan de Vargas de Santafé de Bogotá, y que en el pasado mes de mayo de 2008 presentó la historiadora Paula Ronderos. ${ }^{10}$ Las descripciones médicas - quirúrgicas de este autor no tienen pares en lo que hoy es Colombia sino hasta finales del siglo XIX, cuando ya la anestesia, asepsia y antisepsia habían generado una revolución médica indiscutible.

En conclusión el trabajo de Pedro López de León debe ser considerado como la primera obra quirúrgica de la historiografía médica colombiana y sus dibujos de instrumentos quirúrgicos como los primeros elaborados en América. 


\section{Referencias}

1. Sotomayor Tribín, H. Guerra, enfermedades y médicos en Colombia. Santafé de Bogotá: Escuela de Medicina Juan N. Corpas, Orión Editores; 1997. 365 p.

2. Sotomayor Tribín H, Restrepo E, Gómez A, Pérez M. El medicamento en la historia de Colombia. Santafé de Bogotá: Schering-Plough, Editorial Nomos; 1997. $225 \mathrm{p}$.

3. Sotomayor Tribín, Hugo. Sifilis y pián: a propósito del morbo gálico en la obra de Pedro López de León. Cartagena de Indias de finales del siglo XVI y comienzos del XVII. En: Temas médicos. Santafé de Bogotá: Academia Nacional de Medicina; 2003. p. $125-43$.

4. Solano Alonso J. Salud, cultura y sociedad en Cartagena de Indias, siglos XVI y XVII. Santafé de Bogotá: Fondo de Publicaciones Universidad del Atlántico, Estrategias Educativas; 1998. 365 p.

5. Cid F. Museología Médica. Aspectos teóricos y cuestiones prácticas. Bilbao: Museo Vasco de Historia de la Medicina y de la Ciencia; 2007.
6. López de León P. Práctica y teórica de las apostemas. Catalayud: Impresor Cristóbal Galibez; 1685.

7. Cirugía del renacimiento. Italia-España-Inglaterra. En: Laín Entralgo P. Historia universal de la medicina. Barcelona: Masson Multimedia; 1998.

8. Medicina y sociedad en la España renacentista: la enseñanza de la medicina. En: Laín Entralgo, Pedro. Historia Universal de la Medicina. Barcelona: Masson Multimedia; 1998.

9. Guerra F. Las heridas de guerra contribución de los cirujanos españoles en la evolución de su tratamiento. Bucaramanga: Universidad de Santander. Facultad de Medicina. Cátedra de Historia de la Medicina; 1981. p. 86.

10. Ronderos P. De objetos a artefactos: el oficio de la barbería en el Nuevo Reino de Granada del siglo XVII. En: La huella de los objetos, segundas jornadas internacionales de arte, historia y cultura colonial; 2008 mayo 21-24; Bogotá: Museo de Arte Colonial , Museo Iglesia Santa Clara; 2008. 